\title{
Anexo 1. Glosario
}

\author{
MARÍA PAZ CORVALÁN B.*
}

\section{Definiciones operativas ${ }^{1,2}$}

Abandono del tabaco: Proceso de detener el consumo de cualquier producto de tabaco, con o sin ayuda.

Adicción al tabaco/dependencia del tabaco: Manifestaciones comportamentales, cognitivas y fisiológicas que se desarrollan tras un consumo repetido, y que suelen consistir en un intenso deseo de consumir tabaco, dificultad para controlar ese consumo, persistencia en éste pese a sus consecuencias graves, asignación de mayor prioridad al consumo de tabaco que a otras actividades y obligaciones, aumento de la tolerancia $\mathrm{y}$, en ocasiones, un estado físico de abstinencia.

Consejería: Guía psicológica y asesoramiento práctico en que se entrena a los fumadores para identificar y afrontar los eventos y problemas que se relacionan con fumar, dejar de fumar, o con riesgo de recaída (Ej.: anticipar situaciones estresantes, emplear estrategias de relajación y otras).

Consejería Mínima: Consejo al fumador de menos de 3 minutos por contacto.

Consejería Breve: Intervención de 3 a $10 \mathrm{~min}$ por ocasión y máximo en 4 ocasiones con un tiempo total menor de Intervención.

Consejería Intensiva: Consejería de más de 10 min por encuentro, mínimo 6 sesiones.

Consumidor de tabaco: Persona que hace uso de cualquier producto de tabaco.

Craving: Manifestación intensa del síndrome de abstinencia. Es el deseo imperioso de fumar que se percibe como difícil de refrenar. Lo padecen más del $80 \%$ de los fumadores después de 8 a 12 h sin fumar. Se relaciona con la tasa de recaída.

Desliz: Consumo esporádico de tabaco después de haber dejado de fumar

Día D: Fecha propuesta para dejar de fumar.

Entrevista motivacional: Metodología de enfrentamiento del paciente dirigido y centrado en el ahora cliente, que permite mejorar la relación médico paciente, aumentar la motivación y facilitar el cambio de conductas adictivas y otras

Ex Fumador: Persona que habiendo sido fumador se ha mantenido en abstinencia al menos por los últimos 6 meses.

Fumador: Persona que ha fumado por lo menos un cigarrillo en los últimos 6 meses.

Fumador actual: Persona que fumó algún cigarrillo en los últimos 30 días.

Fumador Diario: Persona mayor de 18 años que ha fumado más de 100 cigarrillos en su vida y fuma por lo menos un cigarrillo al día.

Fumador Ocasional: Persona que ha fumado menos de un cigarrillo al DÍA, durante los últimos 6 meses

Fumador Pasivo: Persona que no fuma, pero que está expuesta y respira humo de tabaco ambiental.

Intervención: Es una acción de mayor duración y frecuencia que un sólo consejo y que se extiende a más de una oportunidad de contacto.

No Fumador: Persona que nunca ha fumado o ha fumado menos de 100 cigarrillos en toda su vida.

Odds Ratio (OR): Valor estadístico que indica la probabilidad que tiene un individuo expuesto a determinada variable de tener el evento comparado a un individuo no expuesto a la variable. Se considera que existe una diferencia estadísticamente significativa cuando sus valores son mayores o menores a 1 , y cuando los valores de su intervalo de confianza del 95\% no cruzan el 1 .

Paquetes/año $=$ (paquetes de 20 fumados por día) $\mathrm{x}$ (años de fumador)). Un paquete/año equivale a 1 paquete de 20 cigarrillos fumado al día durante 365 días.

Productos de tabaco: Los productos preparados totalmente o en parte utilizando como materia prima hojas de tabaco y destinados a ser fumados, chupados, mascados o aspirados.

* Programa de Tabaquismo Centro Médico Fundación del Banco Estado.

Coordinadora Comisión Tabaco, Sociedad Chilena de Enfermedades Respiratorias. 
Promoción del abandono del tabaco: Medidas y métodos que abarcan a toda la población y tienen por objeto contribuir a detener el consumo de tabaco; entre esos métodos figura el tratamiento de la dependencia de tabaco.

Recaída: Retorno al comportamiento adictivo o al estilo de vida anterior, luego de un período inicial de abstinencia y de cambio de estilo de vida (como mínimo entre uno y tres meses).

Síndrome de Privación de Nicotina: Conjunto de síntomas que se presentan al dejar de fumar o por reducción significativa del número de cigarrillos caracterizado por ansiedad, irritabilidad, dolor de cabeza, hambre, temblor, trastornos del sueño y deseo urgente por fumar.

Tasa de abstinencia o cesación: Porcentaje de personas que consiguen no fumar por un tiempo determinado.

Terapia Cognitivo-Conductual: Estrategia psicoterapéutica que permite enfrentar las conductas mal adaptativas, a través de la entrega de conocimientos y ciertas técnicas respaldados por la evidencia científica.

Terapia Intensiva Se trata de consultas específicas de cesación del tabaquismo, de más de 10 min de duración, que son parte de un programa de tabaquismo realizadas por profesionales especialmente entrenados para la cesación, pueden ser grupales o individuales.

Tratamiento de Cesación del Tabaquismo: Es la consejería destinada a ayudar a dejar de fumar que implica el uso de terapia cognitiva conductual, entrevista motivacional y medicamentos si es necesario.

\section{Bibliografía}

1.- Guías de Práctica Clínica Nacional del Tratamiento de la Adicción al Tabaco, Argentina.

2.- Tratado de Tabaquismo, $3^{a}$ edición. Carlos Jiménez Ruiz, Karl O Fagerstrom. Biblioteca Aula Médica 2011. 